\title{
An Optimization Study for Bridge Design of a Porthole Extrusion Die
}

\author{
Önder Ayer ${ }^{1 *}$, Burcu Gizem Özmen², İsmail Karakaya² \\ 1 Trakya University, Muhendislik Fakultesi Makina Muhendisligi Bolumu, 22100, Edirne, Turkey \\ 2 "eksenAL" Aluminum Extrusion Die Factory, Istanbul, Turkey \\ * Corresponding author's e-mail: onderayer@trakya.edu.tr
}

\begin{abstract}
In this study, a porthole die extrusion simulation was carried out for a box profile by using HyperXtrude Inspire Extrude Metal 2019 which is a FEM based software. Aluminum AA6063 material was the billet material, temperature of the billet was $450^{\circ} \mathrm{C}$ and ram speed was selected as $5 \mathrm{~mm} / \mathrm{sec}$. The die design was obtained according to the shape of the bridges of the porthole die. Finally, the design optimization was achieved by analyzing FEM results. It was obtained that the dies which have curved bridges offer optimum process conditions.
\end{abstract}

Keywords: Porthole Die Extrusion, FEM, Aluminum 6063, stress distribution, die deflection.

\section{INTRODUCTION}

Aluminum is the second most plentiful metallic element and has great attention from many field of industry because of its superior properties such as recyclability, corrosion resistance, high specific strength and especially for its light weight. The aluminum has been used increasingly in the last two decades for various industries. Thin-walled with multi-cavity profiles, intricate shapes, large cross-sections, with lower weighted products were required mostly by aerospace, automotive and transportation industries. Hot extrusion method is a useful tool to obtain complicated profiles with high productivity and porthole dies are generally preferred for this purpose. There are various studies relating with extrusion process using porthole dies.

Qamar et al. [1] studied possible die defects and die correction operations for metal extrusion. They proposed a list of definitions for die defects and their preventive measures and die correction methods. The design phase is generally based on a trial and error method and which is an unefficient way in terms of time and the amount of scrap. In order to eliminate trial and error method, finite element based softwares have been getting used more often in the last decade. The goal of using FEM simulations is simulations is to predict the temperature distribution, exit velocity of extruded product, material flow and the tool deformation.

Jie et al. [2] carried out FEM simulations and experiments for porthole die to optimize material flow. He et al. [3] investigated the effects of die pockets in the porthole die on the metal flow, temperature distribution and the extrusion load by using two different multi-hole porthole dies with and without pockets in lower die. Engelhardt et al. [4] used Finite Element method to optimize the extrusion process for multi-hole hollow profile extrusion. They carried out simulations by HyperXtrude software for optimum material flow. Yu et al. [5] investigated different types of welding defects from millimeter scale to nanometer scale for porthole die extrusion for different extrusion die structures and process parameters. Yu et al. [6-9] investigated the relation of leg design with welding chamber of the porthole die. They used different die parameters to observe welding quality of extruded profiles by means of microstructure observation, tensile test and fracture analysis. However, there are still empty areas to be studied in terms of die design for more efficient extrusion process and better product quality. 


\section{MATERIAL AND METHODS}

The FEM simulation was carried out for standard box profile by using porthole extrusion die with the support of HyperXtrude software. In this study, it was aimed to propose an optimum leg design of a porthole die for better material flow. The welding quality is highly related with material flow behavior and solid state bonding process. The macro voids are reffered to material flow when microvoids are referred to insufficient solid state bonding. Consequently, the optimum design will lead longer service life for the die and will prevent wasting resources and result more efficient production cycle.

In the simulations, a standard box profile was used as exit profile with the extrusion ratio of 127. Aluminum 6063 material was selected as a workpiece material and billet diameter was $\varnothing 220 \mathrm{~mm}$ and billet length was $700 \mathrm{~mm}$, butt length was selected as $25 \mathrm{~mm}$. Billet temperature was set as $450{ }^{\circ} \mathrm{C}$, die and container temperature was $430{ }^{\circ} \mathrm{C}$ and punch velocity was set to $5 \mathrm{~mm} / \mathrm{s}$. H13 type steel material was used as die material. The Coulomb friction model was selected for the FEM model with the coefficient of 0.3 at the die bearing zone. For more accurate results, the tetragonal mesh distribution was applied to the model.
Extrusion is a process where the material is pushed through a die to obtain a desired a shape which is generally complicated. Manufacturers prefer the hot extrusion method for porthole dies. Figure 1 shows the view of a porthole die with its dimensions. It can be seen from the figure that the upper die part has 4 portholes. The bridge designs of four different porthole die were given in Figure 2 in detail. The material is forced to flow into portholes around the porthole legs to obtain desired shape. The portholes are used to balance the metal flow with the suitable distribution. The number of portholes determine the extrusion load and material flow. When the profile is so complicated, the number of the porthole is important because of the obtaining better material flow and better longitudinal and transverse weld quality.

Four different bridge design were modelled and simulated. The effect of the bridge design on material flow, die deflection, exit speed and temperature of the product and forming load were investigated. The angle and radius was changed comparing the initial die design which has sharp corners. The detailed view for the design study was given in Figure 2.

The FEM simulations were carried out for the same process conditions but for different die designs. Results were analyzed to obtain optimum bridge design for efficient extrusion process.
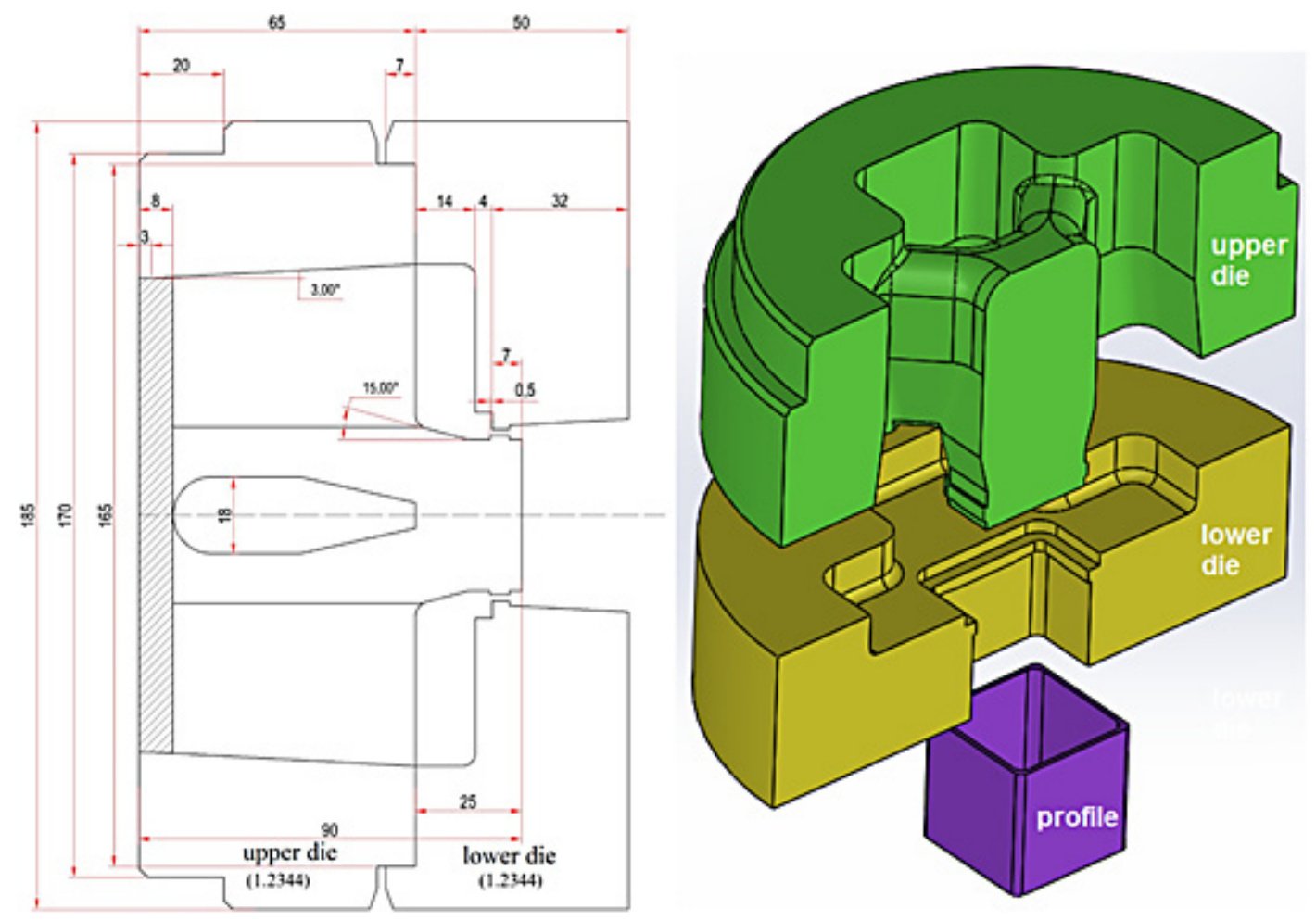

Fig. 1. A view of a porthole die 


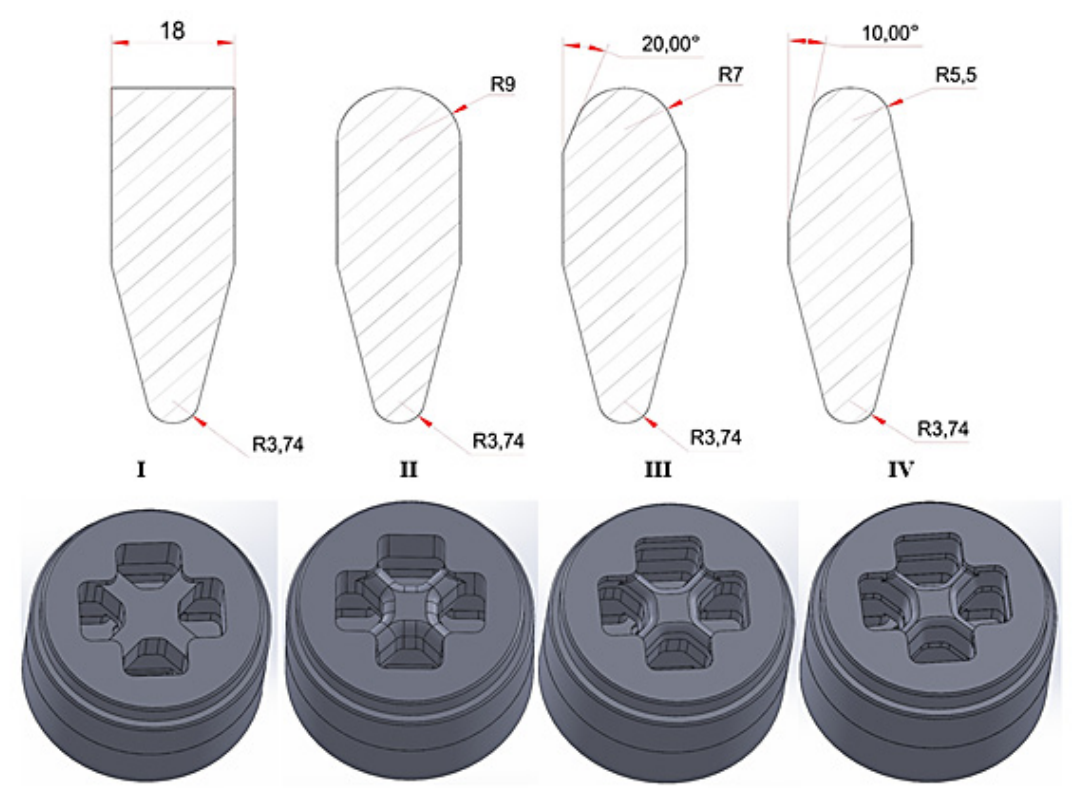

Fig. 2. A view of design of porthole die bridges

\section{RESULTS AND DISCUSSIONS}

The model of the study was built in a commercial CAD software and it was then uploaded to HyperXtrude Inspire Extrude Metal 2019. The calculated results were given in Figures 3-8.

The Figure 3 shows the stress distribution results of the given models. The stress distribution is an important parameter for determining the service life of the die because of affecting the wear of a die. The service life of a die is defined according to the amount of extruded material in tons. The low and homogenous stress distribution promises longer service life.

The die sets are numbered from I to IV with roman letters. It can be seen from the figure that the highest stress values were obtained at die set I. The maximum stress value was calculated about 122.8 MPa for the die set $\mathbf{I}$ and die set $\mathbf{I V}$ gives the minimum stress value which is calculated as $85.2 \mathrm{MPa}$.

It is also observed that stress at the zone A for die set I was calculated between 54-82 MPa when other die sets (II, III and IV) have lower values. The calculated stress range was between 41-68 MPa for die designs II, III and IV at zone $\mathrm{B}$ that is significantly lower than that of the die $\mathbf{I}$. Stress distribution Zone B also shows similarity for the die designs of II, III and IV. It could be observed that the stress at zone $\mathrm{C}$ is highly concentrated on very small area for die set $\mathbf{I}$ and its value is higher than the other die designs.

The die deflection results were given in Figure 4. The amount of die deflection is critical for the accuracy of the extruded profile. When the deflection is higher than the permissible tolerances, the dimensions of the final product could be different that the desired shape which means that the product is scrapped. It could be seen from the figures that die set I gives the highest deflection comparing to other die sets. The deflection is especially high at the mandrel section. The deflection decreases when the radius and angle is implemented to the design hence, the deflection on the mandrel is related with the design of the bridge of the die. It could be observed that the deflection value is in the range of $1.48-1.98 \cdot 10^{-4}$ $\mathrm{mm}$. The deflection distribution for the die set of II, III and IV is different comparing to the initial design where the deflection is accumulated only on the nose of the mandrel section.

The temperature of the profile is important for the dimensional accuracy and mechanical properties of the product. Therefore, it is necessary to predict the exit temperature of the profile. The profile temperature distribution was given in Figure 5. The exit temperature was calculated as $555^{\circ} \mathrm{C}$ on the profile and it is clearly seen that temperature is uniform at the every point of the profile. Initial temperature was $450{ }^{\circ} \mathrm{C}$ and its value decreased because of the heat transfer between billet and container hence the billet temperature was calculated about $442{ }^{\circ} \mathrm{C}$ at the beginning of the process. The temperature of the AA6063 material reached about $555^{\circ} \mathrm{C}$ because of the frictional and stress conditions. The maximum temperature in the die was observed at weld chamber section of the die. That is desirable for obtaining suitable welding conditions. 


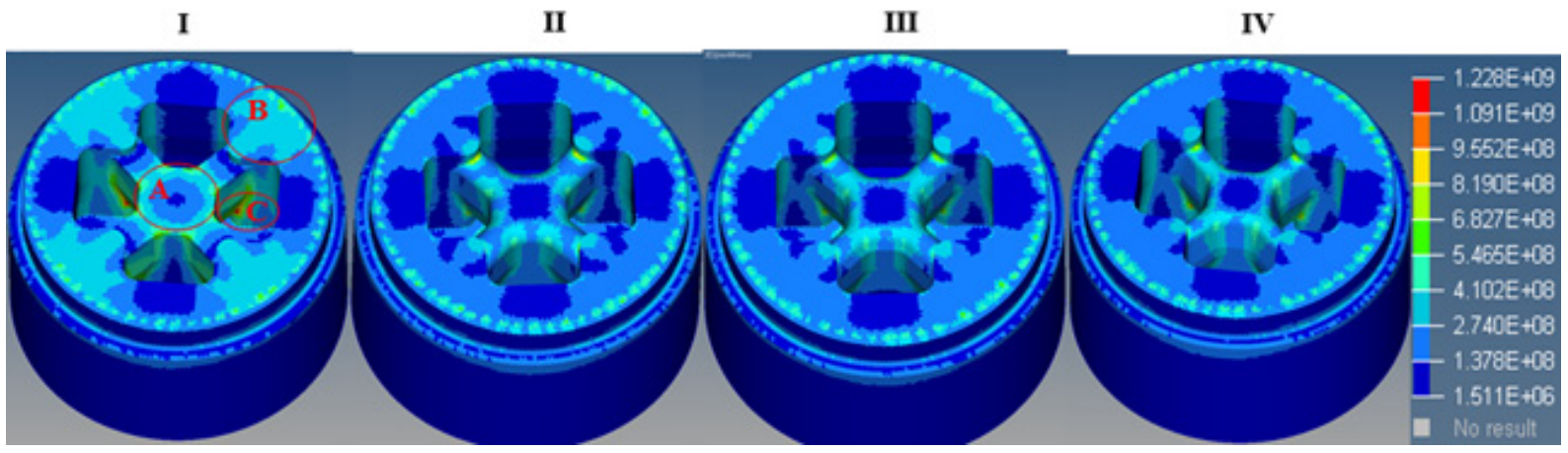

Fig. 3. Stress distribution of the die process $(\mathrm{MPa})$
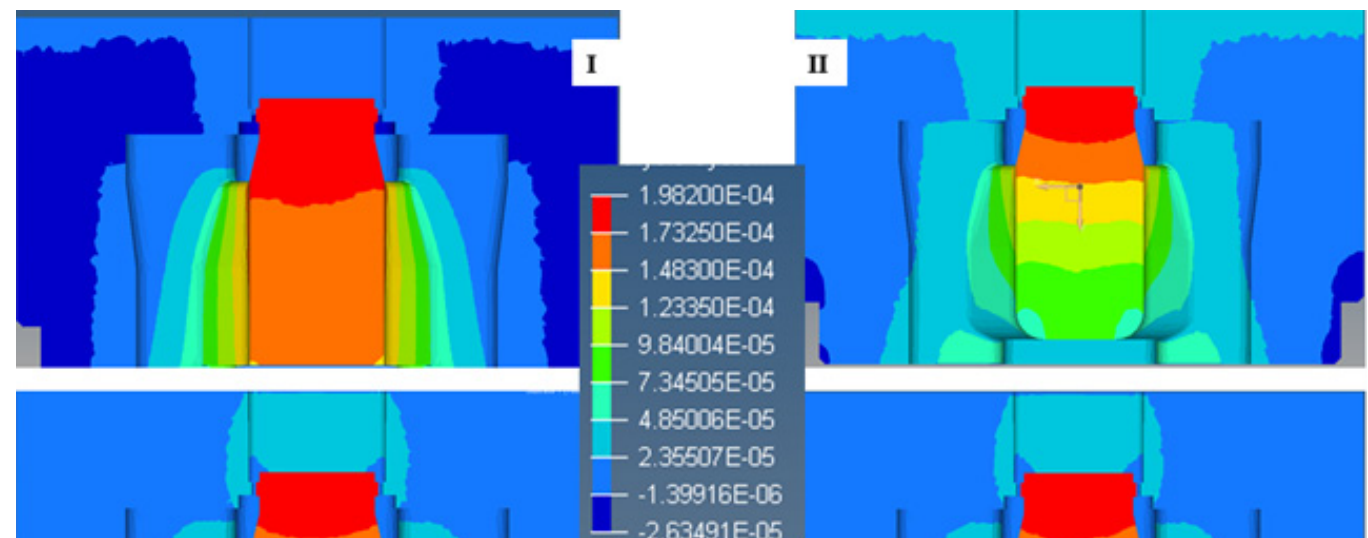

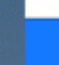

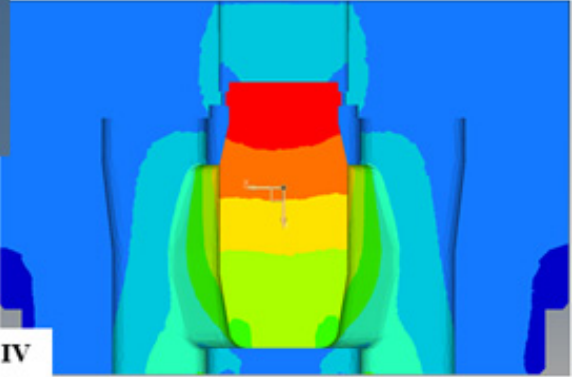

Fig. 4. Die deflection distribution of the extrusion die (mm)

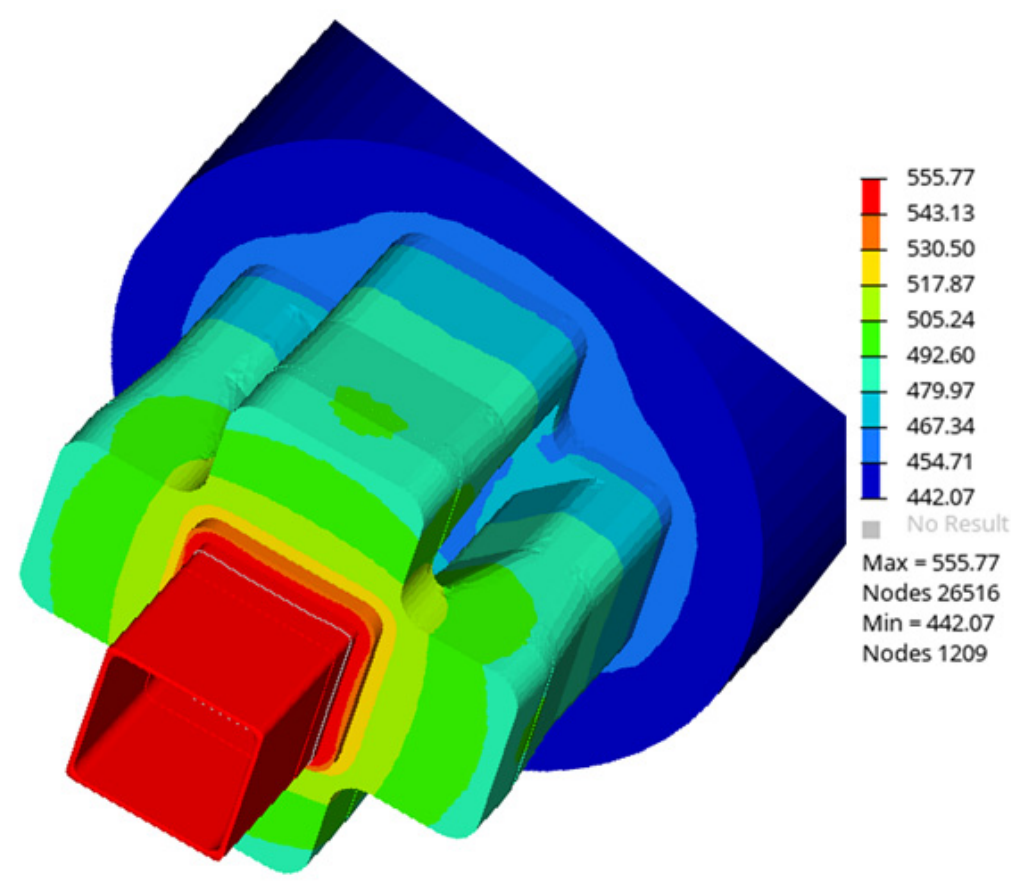

Fig. 5. Temperature distribution of the extruded product 
It is necessary that material flow should be uniform and exit speed of the extruded profile is an important tool for designing the portholes, welding chamber and die bearing zone etc. Figure 6 gives the exit speed of extruded profile. The distortion of the profile could be predicted by using these results. It could be concluded from the figure that the speed distribution on the extruded profile is homogenous. The speed range is $439-440 \mathrm{~mm} / \mathrm{s}$ on the profile for all die sets. There is a negligible difference between speed values of the profiles.
The die temperature distribution was also investigated and the maximum temperature values were recorded. The results were given in Figure 7. It is observed that there is no significant difference between die designs and the temperature distribution is similar. The maximum temperature was calculated at the die sets as but the initial die set has the maximum temperature which is $558.91,557.81,557.20$ and $556.55{ }^{\circ} \mathrm{C}$ respectively. It can be seen that the temperature was concentrated at the die exit.
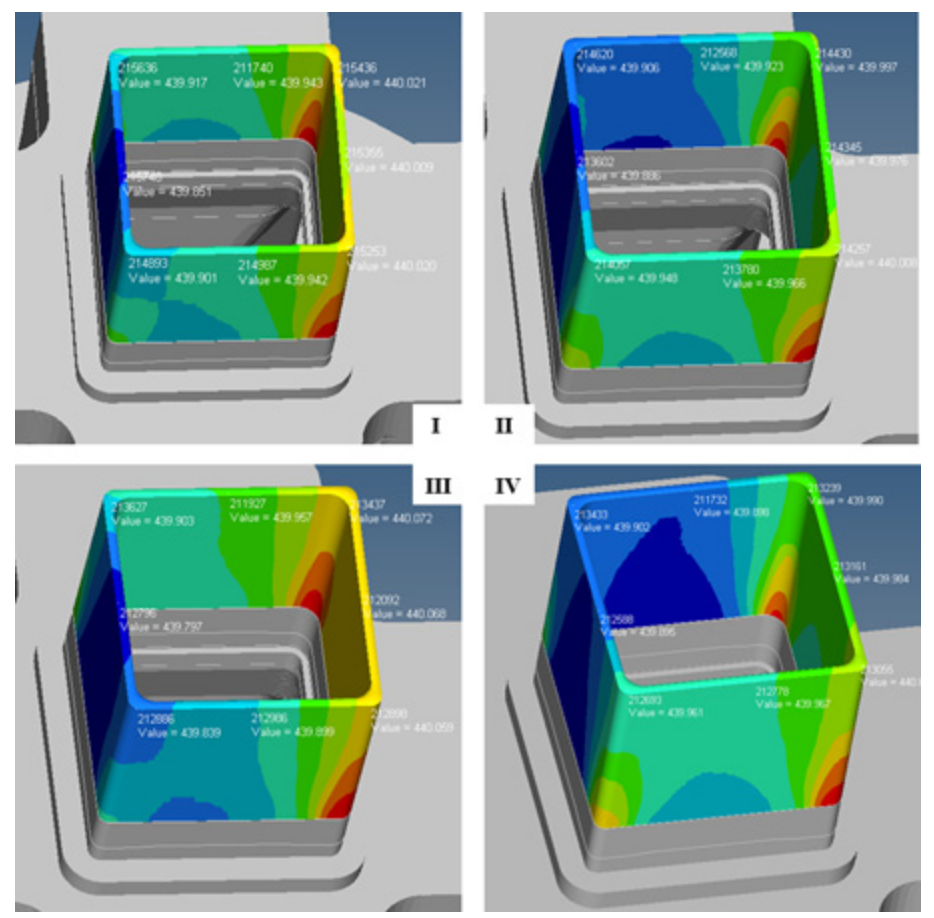

Fig. 6. Exit speed of extruded profile $(\mathrm{mm} / \mathrm{sec})$

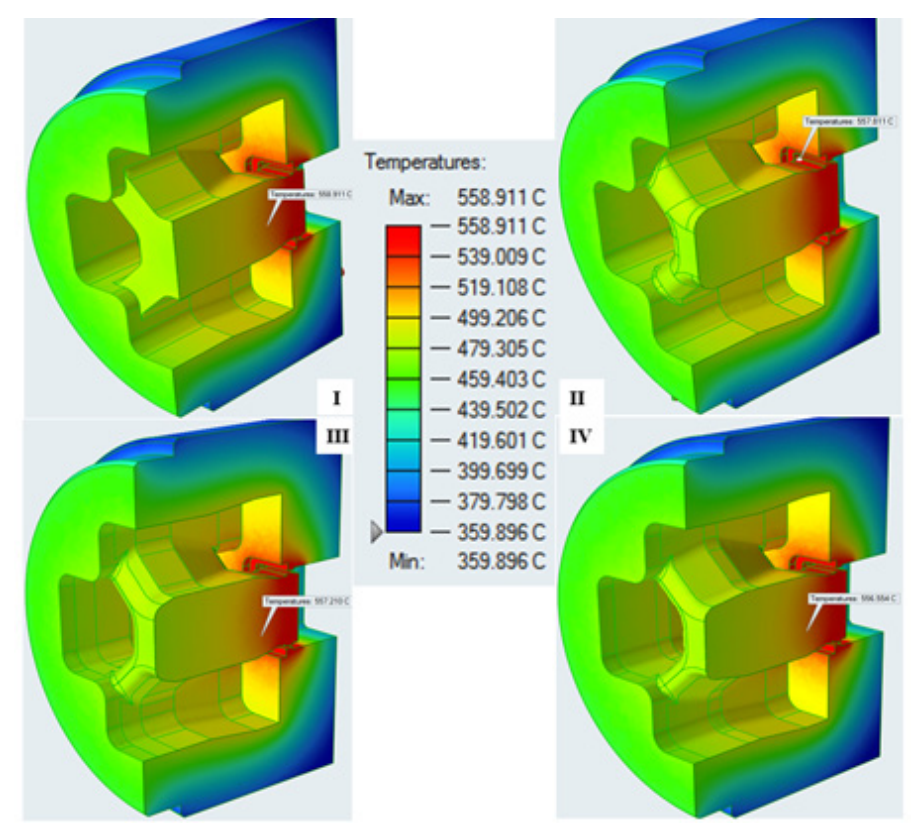

Fig. 7. Temperature distributions of extrusion $\operatorname{dies}\left({ }^{\circ} \mathrm{C}\right)$ 


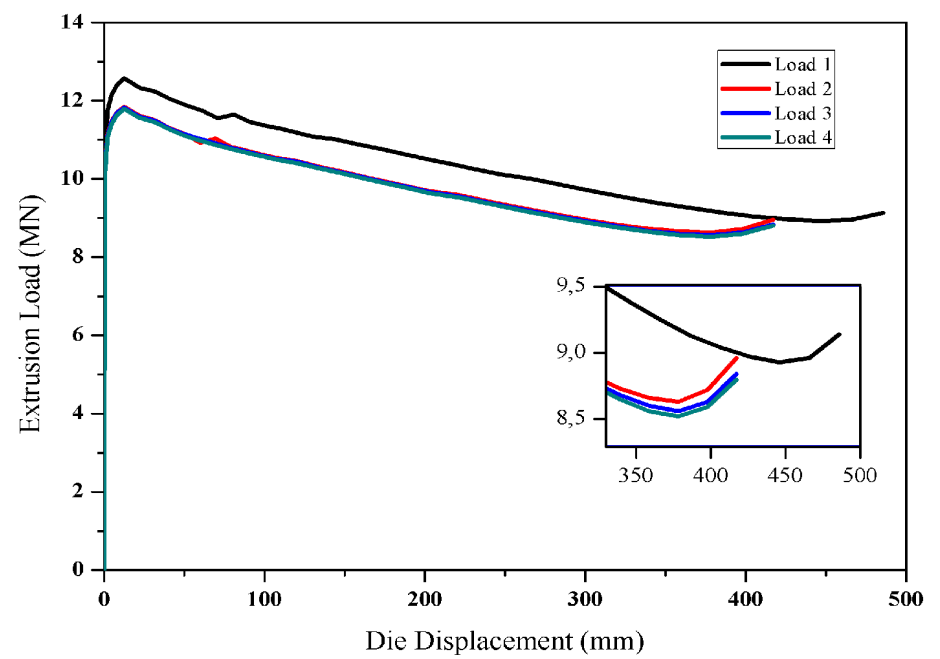

Fig. 8. Extrusion load comparison of die designs

The forming load is the decisive parameter for the selecting the extrusion press capacity. Hence, the forming load was calculated for four different die design and the results were shown in Figure 8. It can be seen from the figure that the initial die requires the maximum forming load and the difference is significant comparing to the other die designs. The die set IV slightly gives the minimum load.

\section{CONCLUSIONS}

In order to obtain optimum bridge design for a porthole extrusion die, the standard box profile was studied by using a FEM based software. The following conclusions were drawn:

1. It was observed that the design of the bridge does not effect the exit speed of the profile.

2. The highest stress values and die deflections were observed in the design of die set I which is the initial die design and other die design values are quite close to each other.

3. The temperature of die sets are quite familiar and it is clear that desing of the bridge has no significant effect on die temperature.

4. The maximum forming load was obtained from the die set I and it could be concluded that the bridge with curved shape relives the material flow and decreases the forming load and stress values.

\section{Acknowledgements}

Authors also wish to thank "eksenAL" Aluminum Extrusion Die Factory for their support for this study.

\section{REFERENCES}

1. Qamar S.Z., Pervez T., Chekotu J.C. 2018. Die defects and die corrections in metal extrusion. Metals (Basel), 8(6).

2. Yi J., Hu Wang Z., Wen Liu Z., Ming Zhang J., He X. 2018. FE analysis of extrusion defect and optimization of metal flow in porthole die for complex hollow aluminium profile/ Trans. Nonferrous Met. Soc. China (English Ed.), 28(10), 2094-2101.

3. He Y.F., Xie S.S., Cheng L., Huang G.J., Fu Y. 2010. FEM simulation of aluminum extrusion process in porthole die with pockets. Trans. Nonferrous Met. Soc. China (English Ed.), 20(6), 1067-1071.

4. Engelhardt M., Kurmajev S., Maier J., Becker C., Hora P. 2019. The application of FEA for optimization of die design. Mater. Today Proc., 10, 226-233.

5. Yu J., Zhao G. 2017. Study on the welding quality in the porthole die extrusion process of aluminum alloy profiles. Procedia Eng., 207, 401-406.

6. Yu J., Zhao G., Chen L. 2016. Analysis of longitudinal weld seam defects and investigation of solidstate bonding criteria in porthole die extrusion process of aluminum alloy profiles. J. Mater. Process. Technol., 237, 31-47.

7. Yu J., Zhao G. 2018. Interfacial structure and bonding mechanism of weld seams during porthole die extrusion of aluminum alloy profiles. Mater. Charact., $138,56-66$.

8. Yu J., Zhao G., Chen L. 2016. Investigation of interface evolution, microstructure and mechanical properties of solid-state bonding seams in hot extrusion process of aluminum alloy profiles. J. Mater. Process. Technol., 230, 153-166.

9. Yu J., Zhao G., Cui W., Chen L., Chen X. 2019. Evaluating the welding quality of longitudinal welds in a hollow profile manufactured by porthole die extrusion: Experiments and simulation. J. Manuf. Process., 38, 502-515. 